\title{
Pengaruh Model Pembelajaran Berbasis Masalah Berbantuan Simulasi Interaktif Terhadap Keterampilan Generik Sains Siswa SMA Pada Materi Elastisitas
}

\author{
Fahmi Yahya, Syarif Fitriyanto \\ Program Studi Pendidikan Fisika \\ Universitas Samawa \\ Sumbawa Besar, Indonesia \\ Email: fyahyaadam@gmail.com
}

\begin{abstract}
The aim of this study is to examine the effects of problem based learning model assist with interactive simulation to science generic skill of students. This is an experimental research with pretest-posttest control group design. Data were collected by using generic skill achievement test and analyzed by using mean-difference test and calculating normalized gain scores. Research finding showed that there is significance difference between experimental group and control group. Moreover, mean value for the experimental group is higher than control group. Problem based learning model assist with interactive simulation is better in improving student science generic skill than without interactive simulation.
\end{abstract}

Keywords : problem based learning, interactive simulation, science generic skill

\section{PENDAHULUAN}

Pelajaran fisika sering dianggap sebagai pelajaran yang sulit dan membosankan. Hal ini terjadi karena pemahaman terhadap konsep fisika masih kurang. Siswa cenderung menghafal tanpa memahami materi. Sehingga menimbulkan kesan yang sulit dalam mempelajari fisika. Siswa akan senang belajar fisika jika telah memahami keindahan dan manfaatnya dalam kehidupan. Ketika siswa sudah mulai tertarik, mereka akan bisa lebih mudah dalam menguasai materi fisika yang dipelajari.

Salah satu materi dalam fisika adalah elastisitas. Materi ini meliputi tegangan, regangan, modulus elastisitas, gaya pegas dan energi potensial pegas. Materi ini mengandung beberapa konsep yang sulit divisualisasikan walau di laboratorium sekalipun. Misalnya, pada konsep modulus elastisitas, terdapat kesulitan dalam melakukan pengukuran dan mengubah variabel terkait sesuai dengan tujuan pembelajaran. Selain itu, materi ini juga mengandung cukup banyak persamaan matematis. Sehingga banyak siswa yang mengalami kesulitan dalam memahami materi ini dengan baik [1]. Karakteristik materi elastisitas yang mengandung konsep abstrak dan banyak persamaan, membuat materi ini tidak cukup jika diajarkan dengan metode pembelajaran konvensional.

Proses pembelajaran konvensional yang selama ini diterapkan belum mampu mengembangkan keterampilan berpikir siswa. Hal ini dapat dilihat dari ketidakmampuan siswa dalam memecahkan masalah yang dihadapi dalam kehidupannya. Pembelajaran konvensional yang didominasi oleh ceramah guru lebih banyak memberikan teori-teori yang tidak mengakar pada dunia nyata siswa. Hal inilah yang melatarbelakangi hadirnya berbagai model pembelajaran yang inovatif untuk membantu siswa memahami konsep dengan menghubungkan antara materi dengan kehidupan nyata siswa. Pembelajaran harus dikondisikan agar siswa terlibat secara aktif mengkonstruksi pengetahuannya sendiri untuk 
memahami konsep-konsep yang dipelajari dalam fisika [1].

Salah satu model pembelajaran yang dapat digunakan adalah model pembelajaran berbasis masalah. Model pembelajaran berbasis masalah didasarkan pada prinsip menggunakan masalah sebagai titik awal akuisisi dan integrasi pengetahuan baru. Model pembelajaran berbasis masalah dapat membantu meningkatkan rasa ingin tahu, keterampilan berpikir, dan kreativitas siswa [2]. Terdapat lima fase dalam model pembelajaran berbasis masalah, yaitu (1) mengorientasikan siswa pada masalah, (2) Mengorganisasikan siswa untuk belajar, (3) Membantu penyelidikan mandiri dan kelompok, (4) Mengembangkan dan menyajikan hasil karya serta memamerkannya, dan (5) Menganalisis dan mengevaluasi proses pembelajaran [3].

Perkembangan teknologi menyediakan kesempatan besar untuk dapat memadukan model pembelajaran berbasis masalah dengan pemanfaatan teknologi komputer. Salah satunya dengan menggunakan simulasi interaktif. Simulasi interaktif merupakan salah satu jenis multimedia pembelajaran yang mencoba untuk menyamai proses dinamis yang terjadi di dunia nyata. Simulasi memberikan kesempatan untuk belajar secara dinamis, interaktif dan perorangan. Penggunaan simulasi interaktif dalam pembelajaran dapat meningkatkan penguasaan konsep fisika siswa, konsep-konsep abstrak yang sulit diterima dan dilihat secara langsung dapat lebih mudah dipahami [4]. Bantuan simulasi komputer dalam model pembelajaran berbasis masalah dapat meningkatkan keterampilan berpikir kritis siswa [2].

Selain untuk meningkatkan penguasaan konsep fisika siswa, model pembelajaran berbasis masalah dengan bantuan simulasi interaktif juga diharapkan dapat meningkatkan keterampilan generik sains siswa. Terdapat keterampilan berpikir yang bersifat generik yang dapat dimunculkan melalui pembelajaran fisika yaitu:pengamatan langsung, pengamatan tak langsung, kesadaran akan skala besaran, kemampuan menggunakan bahasa simbolik, kemampuan berpikir dalam kerangka taat azas, kemampuan inferensi logika, kemampuan memahami hukum sebab akibat, kemampuan membuat model matematik, dan kemampuan membangun konsep abstrak [5]. Model pembelajaran berbasis masalah dengan pendekatan inkuiri terbukti dapat meningkatkan keterampilan generik sains siswa [6].

\section{METODE PENELITIAN}

Jenis penelitian yang digunakan adalah penelitian eksperimen. Populasi penelitian adalah kelas XI IPA di SMAN 1 Alas Barat. Teknik pengambilan sampel menggunakan cluster random sampling. Adapun desain penelitian yang digunakan adalah pretestposttest control group design. Dalam rancangan penelitian ini, sampel dibagi dalam dua kelompok kelas yaitu kelas XI IPA 1 sebagai kelas eksperimen dan kelas XI IPA 2 sebagai kelas kontrol. Kelas eksperimen akan mendapatkan perlakuan pembelajaran dengan penerapan model pembelajaran berbasis masalah berbantuan simulasi interaktif, sedangkan kelompok kontrol mendapatkan pembelajaran dengan model pembelajaran berbasis masalah tanpa bantuan simulasi interaktif.

Untuk mengetahui peningkatan keterampilan generik sains siswa, maka dilakukan perhitungan skor gain yang dinormalisasi. Hal ini bertujuan untuk menghindari kesalahan dalam menginterpretasikan perolehan gain setiap siswa. Persamaan yang digunakan adalah: 


$$
g=\frac{s_{\text {post }}-s_{\text {pre }}}{s_{\text {max }}-s_{\text {pre }}} \times 100 \%
$$

Dengan kategori seperti pada Tabel 1.

Tabel 1. Kategori Skor N-gain

\begin{tabular}{cc}
\hline N-gain & Kategori \\
\hline $\mathrm{N}$-gain $>70 \%$ & tinggi \\
$30 \%<\mathrm{N}$-gain $<70 \%$ & sedang \\
$\mathrm{N}$-gain $<30 \%$ & rendah \\
\hline
\end{tabular}

Untuk melihat perbedaan kemampuan siswa sebelum dan sesudah penelitian, maka dilakukan pretest dan postest. Instrumen penelitian berupa 30 soal pilihan ganda yang sudah diujicobakan sebelumnya di kelas lain, dan sudah dianalisis validitas butir soal, reliabilitas tes, daya pembeda, serta indeks kesukaran tiap butir soal.

Statistik uji yang digunakan adalah uji-t dua pihak. Hasil pretest dan posttest kelas eksperimen dan kelas kontrol diolah dengan membandingkan selisih kedua mean untuk menunjukkan perbedaan keduanya dengan uji-t [7]. Pengolahan data ini diawali dengan uji prasyarat berupa uji homogenitas dan uji normalitas. Uji-t dilakukan untuk mengetahui ada tidaknya pengaruh perlakuan yang diberikan pada kelas eksperimen dan kelas kontrol terhadap keterampilan generik sains siswa kelas XI IPA SMAN 1 Alas Barat.

\section{HASIL DAN PEMBAHASAN}

Tujuan penelitian yang ingin dicapai dalam penelitian ini adalah untuk mengetahui pengaruh model pembelajaran berbasis masalah berbantuan simulasi interaktif terhadap keterampilan generik sains siswa kelas XI IPA SMAN 1 Alas Barat. Adapun indikator keterampilan generik sains yang diukur dalam penelitian ini adalah kemampuan pengamatan tak langsung, kesadaran akan skala besaran, kemampuan inferensi logika, kemampuan memahami hukum sebab akibat, pemodelan matematik, dan kemampuan membangun konsep. Pemilihan indikator tersebut didasarkan pada karakteristik materi elastisitas.

Data penelitian diambil dari hasil pretest dan posttest dari kelas eksperimen dan kelas kontrol. Hasil pretest dan posttest kelas eksperimen dan kelas kontrol kemudian diolah dengan membandingkan selisih kedua mean. Pengujian perbedaan mean dihitung dengan persamaan $t$-test.

Dari hasil pretest didapatkan data seperti dalam Tabel 2. Sedangkan data hasil posttes didapatkan seperti pada Tabel 3 .

Tabel 2. Data Hasil Pretest Keterampilan Generik Sains Siswa.

\begin{tabular}{lcc}
\hline \multicolumn{1}{c}{ Data } & $\begin{array}{c}\text { Kelas } \\
\text { Eksperimen }\end{array}$ & $\begin{array}{c}\text { Kelas } \\
\text { Kontrol }\end{array}$ \\
\hline Jumlah Siswa & 30 & 30 \\
Nilai Tertinggi & 57 & 60 \\
Nilai Terendah & 37 & 30 \\
Nilai Rata-rata & 45 & 45 \\
Standar deviasi & 5.44 & 7.19 \\
Variansi & 29.63 & 51.71 \\
Homogenitas & \multicolumn{2}{c}{ Homogen } \\
\hline
\end{tabular}

Berdasarkan data pretest, tampak bahwa kelas eksperimen dan kelas kontrol memiliki nilai rata-rata yang sama, Nilai tertinggi dan nilai terendah kedua kelas pun tidak jauh berbeda. Uji homogenitas dilakukan menggunakan uji $\mathrm{F}$ dengan taraf signifikansi $5 \%$, didapatkan nilai $\mathrm{F}$ hitung 1,745 . Nilai ini lebih kecil dari nilai $F$ tabel 1,86 sehingga disimpulkan bahwa kedua kelas homogen. Hal ini menandakan bahwa kedua kelas memiliki kemampuan yang relatif sama.

Tabel 3. Data Hasil Posttest Keterampilan Generik Sains Siswa.

\begin{tabular}{lcc}
\hline \multicolumn{1}{c}{ Data } & $\begin{array}{c}\text { Kelas } \\
\text { Eksperimen }\end{array}$ & $\begin{array}{c}\text { Kelas } \\
\text { Kontrol }\end{array}$ \\
\hline Jumlah Siswa & 30 & 30 \\
Nilai Tertinggi & 97 & 87 \\
Nilai Terendah & 53 & 47 \\
Nilai Rata-rata & 79 & 69 \\
Standar deviasi & 12.11 & 10.30 \\
Variansi & 146.67 & 106.09 \\
Homogenitas & \multicolumn{2}{c}{ Homogen } \\
Uji Normalitas & Normal & Normal \\
\hline
\end{tabular}


Berdasarkan data hasil posttest, tampak bahwa kelas eksperimen memiliki nilai ratarata yang lebih tinggi daripada kelas kontrol, Nilai tertinggi dan nilai terendah kelas eksperimen juga lebih tinggi dari kelas kontrol. Dari hasil uji homogenitas pada data postes, didapatkan nilai $F$ hitung 1,382. Nilai ini lebih kecil dari nilai $F$ tabel 1,86 sehingga disimpulkan kedua kelas homogen.

Uji normalitas dilakukan pada data keterampilan generik sains kelas eksperimen didapatkan nilai $X^{2}$ hitung sebesar 4,977, sedangkan pada kelas kontrol didapatkan nilai $\mathrm{X}^{2}$ hitung 8,616. Disimpulkan bahwa kedua kelas terdistribusi normal karena nilai $\mathrm{X}^{2}$ hitung pada kedua kelas lebih kecil dari $\mathrm{X}^{2}$ tabel pada taraf signifikansi 5\% yaitu 11,070.

Hasil pretest dan posttest kelas eksperimen dan kelas kontrol kemudian diolah dengan membanding-kan selisih kedua mean. Pengujian perbedaan mean dihitung dengan persamaan t-test. Dari hasil perhitungan diperoleh bahwa $\mathrm{t}$ hitung $=2.975$ dan $\mathrm{t}$ tabel $=$ 1,684 pada taraf signifikan $5 \%$ dengan $\mathrm{db}=$ $(30+30-2)=58$. Karena $-t$ tabel $<t$ hitung atau $\mathrm{t}$ hitung $>+\mathrm{t}$ tabel, maka Ha diterima dan Ho ditolak. Hal ini menunjukkan bahwa terdapat perbedaan pengaruh antara model pembelajaran berbasis masalah berbantuan simulasi interaktif dengan model pembelajaran berbasis masalah tanpa bantuan simulasi interaktif terhadap keterampilan generik sains fisika siswa kelas XI IPA SMAN 1 Alas Barat.

Perbandingan persentase skor rerata pretest, posttest, dan $\mathrm{N}$-gain keterampilan generik sains antara kelas eksperimen dan kelas kontrol ditampilkan dalam Gambar 1.

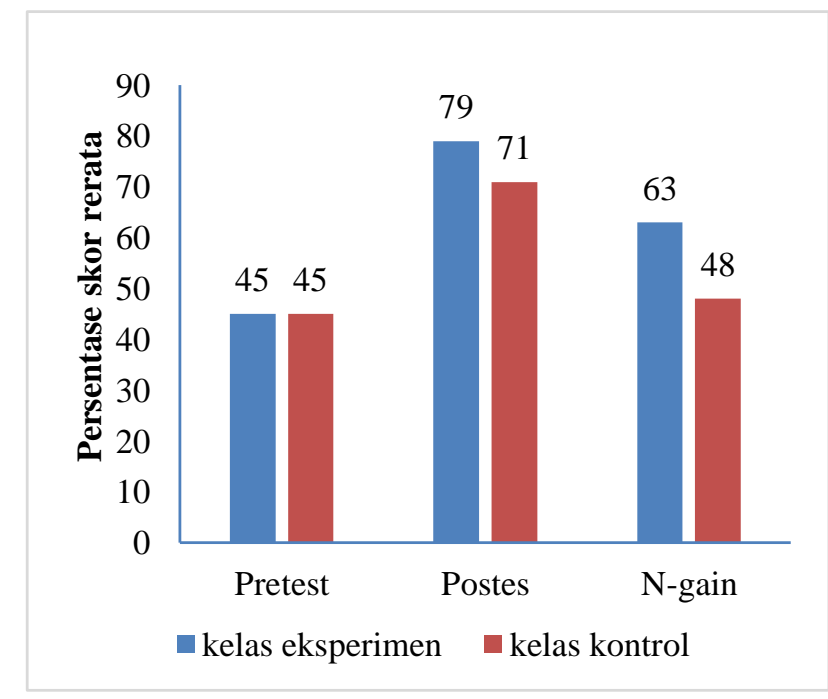

Gambar 1. Perbandingan persentase skor pretest, posttest, dan $\mathrm{N}$-gain keterampilan generik sains kelas eksperimen dan kelas kontrol.

Berdasarkan data peningkatan persentase skor N-gain, dapat diketahui bahwa terdapat skor peningkatan keterampilan generik sains pada kedua kelas. Namun, peningkatan keterampilan generik sains siswa kelas eksperimen lebih besar yaitu $63 \%$ jika dibandingkan dengan kelas kontrol yang hanya $48 \%$. Hal ini menunjukkan bahwa penggunaan bantuan simulasi interaktif dalam model pembelajaran memberikan pengaruh yang lebih baik dalam meningkatkan keterampilan generik sains siswa, khususnya pada kemampuan pengamatan tak langsung, kesadaran akan skala besaran, kemampuan inferensi logika, kemampuan memahami hukum sebab akibat, pemodelan matematik, dan kemampuan membangun konsep.

Temuan dalam penelitian ini semakin menguatkan teori bahwa simulasi interaktif sebagai multimedia pembelajaran dapat digunakan untuk meningkatkan penguasaan konsep, keterampilan generik sains, dan keterampilan berpikir kritis siswa serta menjadikan siswa terlibat secara aktif dalam pembelajaran [1][4]. Model pembelajaran berbasis masalah berbantuan simulasi interaktif lebih baik dari model pembelajaran 
konvensional dalam meningkatkan penguasaan konsep dan keterampilan generik sains siswa [2][6].

Penggunaan simulasi interaktif dalam pembelajaran terbukti mampu meningkatkan keterampilan berpikir siswa karena dapat memvisualisasikan konsep-konsep abstrak dan menyajikan proses fisis dengan lebih lengkap. Dengan simulasi interaktif, siswa menjadi lebih leluasa dalam melakukan percobaan fisika, mengeksplorasi secara bebas, belajar memprediksi, mencoba membuktikan kebenenaran prediksinya, hingga dapat menemukan sendiri konsep fisika yang sedang dipelajarinya [1]

\section{PENUTUP}

Berdasarkan hasil penelitian, maka disimpulkan bahwa terdapat perbedaan pengaruh yang signifikan antara model pembelajaran berbasis masalah berbantuan simulasi interaktif dengan model pembelajaran berbasis masalah tanpa bantuan simulasi interaktif pada keterampilan generik sains fisika siswa kelas XI IPA SMAN 1 Alas Barat. Model pembelajaran berbasis masalah berbantuan simulasi interaktif lebih baik dalam meningkatkan keterampilan generik sains fisika siswa.

Berdasarkan hasil penelitian, pembahasan dan kesimpulan, maka terdapat beberapa saran, yaitu: (1) Model pembelajaran berbasis masalah menuntut peneliti untuk lebih kreatif dalam penerapannya. Peneliti harus mampu mengorganisasikan pembelajaran di sekitar masalah-masalah yang hendak dicari penyelesaiannya. (2) Jika menggunakan bantuan simulasi interaktif, peneliti harus mampu menyajikan simulasi yang benar-benar sesuai dengan konsep fisika yang hendak dicari penyelesaiannya. (3) Peneliti juga diharapkan bisa memanfaatkan waktu secara maksimal agar tidak menganggu program pembelajaran yang sudah direncanakan. (4) Untuk penelitian selanjutnya, penggunaan model pembelajaran berbasis masalah berbantuan simulasi interatif dapat dilakukan pada materi, indikator, dan kompetensi dasar yang berbeda dengan subjek penelitian yang lebih luas.

\section{REFERENSI}

[1] Gunawan. (2008). "Pembelajaran Berbasis Multimedia Interaktif untuk Meningkatkan Keterampilan Generik Sains Calon Guru Fisika". Jurnal Pijar MIPA, III (1): 1-5.

[2] Herayanti, L., Habibi. (2015). "Model Pembelajaran Berbasis Masalah Berbantuan Simulasi Komputer untuk Meningkatkan Keterampilan Berpikir Kritis Calon Guru Fisika”. Jurnal Pendidikan Fisika dan Teknologi, 1(1): 61-66.

[3] Nur, Muhammad. (2011). Model Pembelajaran Berdasarkan Masalah. Surabaya: Pusat Sains dan Matematika Sekolah UNESA.

[4] Gunawan. (2011). "Model multimedia interaktif elastisitas dan implikasinya terhadap peningkatan penguasaan konsep dan keterampilan berpikir kritis mahasiswa". Jurnal Kependidikan, 10 (1).

[5] Brotosiswoyo, B.S. (2001). Hakikat Pembelajaran Fisika di Perguruan Tinggi: Fisika. Jakarta: PAU-PPAI Dirjen Dikti Depdiknas.

[6] Herayanti, L. (2012). "Model Pembelajaran Berbasis Masalah dengan Pendekatan Inkuiri untuk Meningkatkan Keterampilan Generik Sains Mahasiswa”. Jurnal Kependidikan, Vol 11 No. 1. 
[7] Arikunto,Suharsimi. (2006). Prosedur Penelitian. Jakarta: Rineka Cipta.

\section{Biografi Penulis}

Fahmi Yahya, M.Pd. Lahir di desa Gontar kabupaten Sumbawa pada tanggal 21 April 1991. Kuliah di Jurusan Pendidikan Fisika Universitas Mataram dan mendapatkan gelar Sarjana Pendidikan di tahun 2012. Melanjutkan studi di tahun berikutnya di program pascasarjana Universitas Negeri Malang dengan jurusan yang sama dan mendapat gelar Magister Pendidikan di tahun 2015. Mulai mengabdi menjadi dosen di Universitas Samawa sejak tahun 2015.

Syarif Fitriyanto, M.Pd. Lahir di Sumbawa pada tanggal 12 Mei 1988. Kuliah di jurusan pendidikan fisika Universitas Samawa dan mendapatkan gelar Sarjana Pendidikan tahun 2010. Melanjutkan studi di tahun 2013 di program pascasarjana Universitas Negeri Semarang jurusan Pendidikan IPA dengan konsentrasi fisika, dan mendapatkan gelar magister pendidikan di tahun 2015. Saat ini mengabdi sebagai dosen di Universitas Samawa. 